\title{
Silent Reading of Music and Texts; Eye Movements and Integrative Reading Mechanisms
}

\author{
Michel A. Cara \\ Pontificia Universidad Católica de \\ Valparaíso
}

\author{
Gabriela Gómez Vera \\ Universidad de Chile
}

\begin{abstract}
This study investigates to what extent structural units defined by physical and structural markers elicit different eye movement patterns when reading contrasting stimuli of music and verbal texts. Eye movements were tracked and compared in ten musicians undergoing Bachelor's degrees as they silently read six texts and six pieces of music for piano: the music was contemporary, in modal style, and the style of the texts was informative and literary. Participants were music students at Universidad de Chile studying for Bachelor's degrees. Information integration for both local (intrasentence/phrase) and global (intersentence/phrase) levels of processing was assessed through regressive fixations at the first pass and re-reading stages. Memory involvement in musical and verbal processing was investigated using verbal working memory and spatial memory tasks, suggesting a link between spatial memory and the reading of contemporary music. Both local and global integrative controls vary according to the reading stages, with differences between music styles and text types. These differences relate to information intake and integrative reading mechanisms. Despite the fact that musicians used different strategies for processing verbal and musical information, no cross-patterns of individual reading strategies were observed between conditions. Although the underlying processes are different, resource-sharing between the two domains cannot be ruled out.
\end{abstract}

Keywords: Eye-movements, integrative mechanisms, music reading, text reading, working memory, spatial memory, saccades, eye-tracking, visual memory

\section{Introduction}

\section{Music and Text Reading}

The study of music and text reading, particularly with eye-tracking techniques, has developed gradually in recent years and continues to gain interest. Despite this,

Received May 5, 2016; Published October 15, 2016.

Citation: Cara, M. A. \& Gómez Vera, G. (2016). Silent reading of

music and texts; eye movements and integrative reading mecha-

nisms. Journal of Eye Movement Research, 9(7):2, 1-17.

Digital Object Identifier: $10.16910 /$ jemr.9.7.2

ISSN: 1995-8692

This article is licensed under a Creative Commons Attribution 4.0 International license. $(\boldsymbol{c c}) \mathbf{E r}$ establishing comparisons between music and language processing is still not simple. In fact, interpretation of syntax, semantics and phonology cannot be subjectively transferred from one domain to another (ThompsonSchill, 2013). Additionally, the natures of hierarchical structures in music and language differ (Asano \& Boeckx, 2015) and are not always in accordance with one another (Arbib, 2013).

Moreover, it is not yet possible to establish whether score reading and text reading are functionally independent, particularly in learning (Madell \& Hebert, 2009) or in high-level cognitive processes. It is for this reason that the study of eye movements can provide new evidence for better understanding the cognitive mechanisms under- 
lying complex processes in music and language (Rayner, Chace, Slattery \& Ashby, 2006).

Both music and verbal texts are determined by structural and visual features that are hierarchically organized. In the particular case of western music, tonal distances determine the hierarchical organization of musical structures (Schön et al., 2007). From this perspective the sentence (small-scale structure) represents, as stated by Sloboda $(1974,1977)$, a relevant unit of comparison between music and text reading. This author pointed out that structural markers ${ }^{1}$ are related to musical processing (e.g. spacing of notes, articulations) and that musicians use both structural and physical markers when reading music. This suggests that parallels exist between music and language processing at high levels of abstraction. Additionally, markers can help the reader extract and connect ideas from the text to larger units that represent a main theme (Graesser, McNamara, \& Louwerse, 2003).

To date most music reading studies, with some exceptions, have been based on short musical passages or excerpts or the analysis of low level process (Servant \& Baccino, 1999). As a consequence, there is little understanding of how musical information is processed with respect to its more general context. In fact, large-scale music processing (narrative or discourse in language) involves the construction of meanings at different levels: sentence-by-sentence, cumulative and structural (Seyfert et al., 2013). Furthermore, large-scale structure processing depends on surface information interpretation as well as global factors that are reliant on the meaning of symbols (Kinsler \& Carpenter, 1995).

\section{Eye Movement Measurements in Music and Text Reading}

Different eye movement measurements have been used to study reading, including the number and duration of fixations, type of fixations (regressive or progressive) and the amplitude of saccades. Other measurements are more specific, although not exclusive to the study of eye movements in text reading. For example the first pass or

1 "The structural markers define a unit in terms of sequential rules to obey his constituents "..." The physical markers enable the definition of a unit before the analysis of its components" (Sloboda, 1977, p. 117). second pass, which refer respectively to the total length of fixations in the first and second inspections of the text (Rayner, 1998; Johansson, Holmqvist, Mossberg, \& Lindgren, 2012). Similar measurements have been used to study the oculomotor behaviour associated with music reading without the corresponding motor execution. There is some evidence that fixation durations in language are shorter than in music reading. Bigand et al. (2010) reported an average fixation duration of $375 \mathrm{~ms}$ for music and two subsets for language, between 225-250 $\mathrm{ms}$ for silent reading and $175-325 \mathrm{~ms}$ for oral reading. Rayner \& Pollatsek (1997) reported an average fixation duration of $350-400 \mathrm{~ms}$ for music and $200-250 \mathrm{~ms}$ for silent reading of English text. However, other studies have reported longer fixation durations of $377-474 \mathrm{~ms}$ (Goolsby, 1994a) and $730 \mathrm{~ms}$ (Penttinen, Huovinen \& Ylitalo, 2015). Duration of fixations is an indicator of difficulties in information processing (Baccino, 2004; Baccino \& Colombi, 2001; Bigand et al., 2010, Goldberg \& Kotval, 1999; Goldberg \& Schryver, 1995; Holmqvist, Holšánová, Barthelson, \& Lundqvist, 2003; Rayner, 1998).

Previous research (Sloboda, 1977; Goolsby, 1994b; Kinsler \& Carpenter, 1995) has indirectly addressed the comparison of eye movements in reading music and text without studying this theme exclusively in single experiments, for example during silent reading or sight-reading. In the present study we directly compare eye movement patterns of music students performing a silent reading task of music and texts. Physical and structural markers will serve as boundaries defining small-scale structures as comparison units between the two domains.

\section{Silent Reading and Sight-Reading}

Silent reading is based on the absence of performance in the case of music, or of reading aloud in the case of texts. Silent reading studies are more commonly associated with reading texts (see Rayner, 1998), and we can find a wide range of tasks to evaluate eye movements while reading. For example: yes/no comprehension questions after reading sentences including some target words (Ashby \& Clifton, 2005); free reading of text passages and pseudoword lists (Hutzler \& Wimmer, 2004). In contrast, silent music reading studies are not so frequent and the main tasks described are related to information extraction such as: search through the musical phrases for errors (Gilman \& Underwood, 2003); recognizing certain 
musical patterns (Burman \& Booth, 2009); indicating whether a new musical stimulus is the same or different from the preceding one (Waters, Underwood \& Findlay, 1997, Waters \& Underwood, 1998); silent reading before performance/humming (Polanka, 1995); or even tasks assessing personal strategies for musical stimuli inspection, for example free silent reading (Penttinen, Huovinen, \& Ylitalo (2013) or careful reading of a score in order to answer questions about the musical theme presented (Servant \& Baccino, 1999).

The average duration of fixations in silent music reading studies using stimuli of four or more bars ranged from 242-2,004 ms (Servant \& Baccino, 1999; Gilman \& Uderwood, 2003; Drai-Zerbib, Baccino \& Bigand 2012; Penttinen et al., 2013; Drai-Zerbib \& Baccino, 2014). In studies that included less than 4 bars of musical stimuli, fixation duration ranged from 193-309 ms (Waters, Underwood \& Findlay, 1997; Waters \& Underwood, 1998). Some of the conclusions from silent reading studies are that eye movement patterns depend on the visual features of the stimuli and that musicians use "chunking strategies" similar to those used for reading texts (Waters et al., 1997; Waters \& Underwood, 1998). Silent reading also implies high cognitive load demands (Gilman \& Underwood, 2003) and is an important task for studying high level cognitive processes. It can also inform us about integrative reading mechanisms (Servant \& Baccino, 1999; Drai-Zerbib \& Baccino, 2005).

Gilman and Underwood (2003) is one of the few studies addressing music reading through silent reading and music performance. Music stimuli consisted of 3 bars of Bach choral excerpts with the tenor part removed. The authors demonstrate that saccades and fixation durations are longer in a silent reading task (283-388 ms) than in a sight-reading task (284-328 ms). They suggest that these differences could be explained by the fact that in silent reading musicians do not need to read normally from left to right. Furthermore the nature of the silent reading task (error detection) might encourage note-by-note reading.

Sight-reading is more commonly associated with the performance of unrehearsed written music. Few sightreading studies have analysed differences in eye movement patterns between different music styles. Weaver (1943) shows that anticipation capacities are constrained by music texture. There is also evidence that music structure has an effect on anticipation behaviour, revealing musicians' capacity to adapt their eye-hand span to phrase boundaries (Sloboda, 1974, 1977; Wurtz, Mueri, \& Wiesendanger, 2009). Lehmann and Ericsson (1996) show that sight-reading achievement can be predicted based primarily on specialized expertise and to a lesser extent on the number of years of practice. From sightreading studies we also know that musicians develop the ability to identify and processes groups of notes or "chunks" (Kinsler \& Carpenter, 1995; Polanka, 1995; Waters et al., 1997; Wolf, 1976); this could be considered as an element of comparison between the musical and verbal domains as well as the use of horizontal peripheral vision (Goolsby, 1994b). Furthermore, it has been proved that "chunking" abilities correlate with sight reading performances (Waters, Townsend, \& Underwood, 1998).

\section{Eye Movements as an Indicator of Semantic Integration During Reading}

Early theories of eye movement control (Hochberg, 1976) showed that spatial decision depends on the knowledge of syntax and semantics. Progressive fixations occur when the reader is moving forward to obtain information. In contrast, regressive eye fixations occur when the reader returns to previously read text to recover information or improve comprehension, such as occurs when reading complex sentences (Bigand et al., 2010). Re-fixations take place in areas that have already been read, ensuring understanding of syntactic structure from certain indices found in the phrase (Dai-Zerbib \& Baccino 2005). The number of regressive fixations has been described as an indicator of difficulties in information integration (Lévy-Schoen, 1988; Hyönä 1995; Servant \& Baccino, 1999). Furthermore, regressive fixations are influenced by musical complexity (Goolsby, 1994a).

A quite recent review of the literature indicates that there are three main hypotheses for regressions in reading which determine three different, non-exclusive levels of processing: "going from low-level visuomotor processes, to higher-level word identification and sentence comprehension processes" (Vitu, 2005, p. 12). Furthermore, analysis of regressive fixations suggests that there are local and global controls inherent to the cognitive processes of reading that determine coherency, an essential property in comprehension (Servant \& Baccino, 1999).

In a more recent study, Penttinen et al. (2013) examine visual processing and verbal descriptions during silent reading of a music score by different expertise groups (novices and amateur musicians). The authors identified 
three different silent-reading styles: accurate processors, accurate analysers and accurate integrators. Integrator readers use shorter fixation times than other groups. The work of Servant \& Baccino (1999) uses modified and original musical excerpts from Beethoven's Bagatelles as stimuli. The authors show that modified versions of Beethoven's Bagatelles require further global and local information integration. This was demonstrated by a decrease in the number of regressive fixations on the target areas (modified from the original). For the authors, these differences are explained by the processing of the musical facts to capture characteristic features of the composer's work, informing the reader about the mode and place of the intervention of integrative mechanisms (Servant \& Baccino, 1999). These mechanisms serve an important function, to release working-memory (see next section) from superficial representations. This allows the reader to obtain an idea, albeit a limited one, of every word (Just \& Carpenter, 1980, 1987).

\section{Working Memory}

The different processes involved in the integration of information, in order to bind and enrich the new information with that already stored, are held in the working memory system (Servant \& Baccino, 1999). Baddeley (1990) defines working memory as a complex system that temporarily stores and processes information in a series of cognitive tasks. This system consists of two subsystems, the phonological loop and the visuospatial sketchpad, which respond to a central executor responsible for the selection and implementation of control processes. These slave systems are respectively responsible for the maintenance and the processing of verbal and spatial information. The fourth component, the episodic buffer, is attentionally controlled by the executive, combining auditory and visual information (multidimensional code) and serves as an interface between working and long-term memory (Baddeley, 2003).

To determine the inter-individual differences in reading texts, Daneman \& Carpenter (1980) proposed the reading span task. This task aims to measure the capacity of working memory for storing and processing information. The authors observe correlations between reading comprehension outcomes and the results of the reading span task, explained by the implementation of common processes that are linked to the nature of the information triggered (Desmette, Hupet, Schelstraete, \& Van der Linden, 1995). These findings have been corroborated by several studies but have also been challenged by others (see Ehrlich, Brébion, \& Tardieu, 1994; see also Kane et al., 2004, for an overview).

\section{Comprehension in Music and Language}

Verbal comprehension is a process in which the reader interacts with the text through the use of thought and language (Iser, 1997). It therefore implies the use of a series of cognitive and metacognitive skills (Van Dijk \& Kintsch, 1983) mediated by mastering verbal procedures (Byrne, 2005). Text reading involves the simultaneous implementation of a series of activities where the goal is the construction of a representation (Fayol, David, Dubois, \& Rémond, 2000).

Music reading is characterized by a vertical component, or the simultaneous reading of various musical notes, and the integration of agogic nuances, such as changes in tempo. Sequential units are commonly constituted by series of chords represented by a simultaneously or consecutively played group of notes (Sloboda, 1984; Hébert \& Cuddy, 2006).

The literature on music meaning is mainly divided into two interpretations: that music has a self-significance (Arom, 2000); and that musical comprehension can be defined in consideration of a broader view of meaning (Patel, 2008; Koelsch et al., 2004). In the first approach musical meaning can be extracted, for example, from musical form, while in the second approach the relationship between the different structural elements of music (intra-musical references) determines musical meaning. The resolution, stability and continuity of those structural elements allow the large-scale meaning of music to emerge (Koelsch, 2012).

\section{The Present Study}

The goal of the present study was to compare eye movement patterns in music students during a silent reading task of verbal texts and scores. To our knowledge this is the first study that directly compares these two types of reading. The comparison is achieved by considering physical and structural limits of stimuli (small-scale processing) through different musical styles and types of texts (large-scale processing). We chose a silent reading task to compare the two domains as it does not engage motor movement. Unlike previous research, the use of entire, short musical pieces allows us to study information integration mechanisms through the construction of a global representation of the stimuli. 
Firstly, this study aimed to look for differences in eye movements in reading music and verbal texts. We expected longer fixation durations in reading scores, contrasted with an increased number of fixations in reading texts. For regressive fixations, we expected a higher number in the scores as a consequence of twodimensional processing.

Secondly, we aimed to demonstrate that eye movements are sensitive to physical and structural markers which determine different eye movement patterns. These patterns might vary between music styles (tonal and contemporary) and verbal texts (informative and literary) depending on: (1) the occurrence of integrative controls (regressive fixations) in both local and global levels, and (2) the reading stage in which they occur (first-pass and re-reading).

\section{Methods}

\section{Participants and Stimuli}

Ten Bachelor of Music students studying functional piano, between the third and fifth year in the Faculty of Arts of the University of Chile, participated in the study. The participants were all students of the same piano teacher. Their age varied between 21 and 26 years $(\mathrm{M}=$ 23.4, $S D=1.5)$, with piano playing experience between 3 and 11 years $(M=6.05, S D=2.89)$ and music reading experience between 2 and 8 years $(M=4.8, S D=2.29)$. It is important to note that the range of music experience includes both formal and informal experiences. However, informal experiences did not allow the students to advance to more difficult courses in the Bachelor programme (at least in reading). Musical background was evaluated by self-reports considering music reading experience and hours of piano training. This research was conducted prior to the approval of the review committee of the Faculty of Arts at the University of Chile. Participants were verbally informed about the purpose and procedures of the research, as well as the alternatives. All 10 pianists voluntarily accepted to participate in the experiment without any outside influence, and confidentiality was assured. The authors complied with ethical practices for the purpose of this research.

Six contrasting styles for both scores (tonal and contemporary) and texts (informative and literary) were selected. Musical stimuli were chosen based on two crite- ria: historical (time periods) and hierarchical organization (tonal vs atonal scores). The stimuli were extracted from two sources: the Notenmappe, a pedagogical book containing collections of musical pieces composed in classical-romantic style, and a book published by the Faculty of Arts of the University of Chile containing short pieces by contemporary pianists (Botto, 1965). The contemporary scores were composed by Leni Alexander, a PolishJewish musician who came to settle in Chile as a refugee in 1939. These musical pieces were created within a pedagogical context, adopting the concept of dissonance but maintaining similar construction to traditional counterpoint. Due to the era in which they were composed (1950s) and the composer's rejection of tonality, these pieces can be considered as contemporary but neither experimental nor avant-garde. Scores were selected with the following criteria: (1) an equivalent number of notes, bars and semi-phrases; (2) not more than two lines, double stave each (see Figure 1 and Table A1). All musical stimuli were full pieces with the exception of one Notenmappe score (Gavotte).

Verbal texts were selected according to the age and education of participants. Lexile measures ranging between 1240L and 1470L were used. These levels represent a reading level suitable for students finishing high school or in their first year of university (Wright \& Stenner, 1998). The average sentence and word lengths were 34.15 and 4.7 characters, respectively. Literary and expositive texts were chosen as they generally have contrasting rhetorical structures, paragraph organization and

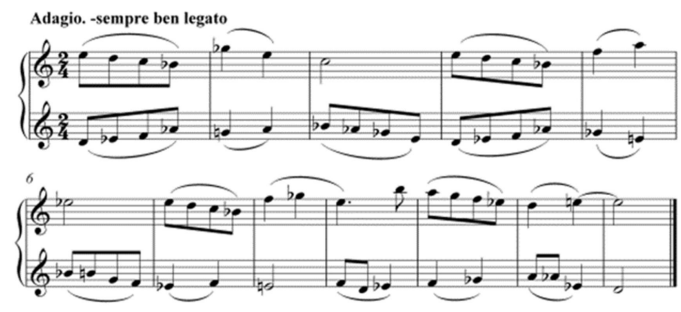

Figure 1. One of the selected contemporary musical stimuli by composer Leni Alexander. The piece is structured in 4 semi-phrases: first semi-phrase (bars 1-3), second (bars 46), third (bars 7-9), and fourth (bars 10-12). When fixations land in the same semi-phrase it is considered an intraphrase fixation. In contrast, when fixations land across multiple bars (adjacent or not adjacent) it is considered an inter-phrase fixation (e.g. from bars 2 to 7 or from bars 2 to 4). 
levels of communication (implicit $v s$ explicit) (Graesser et al., 2003). The number of small-scale structure units (musical semi-phrases and sentences) are equivalent in number between the musical and verbal stimuli (see Table A1 and table A2).

\section{Eye-Tracking Equipment}

Eye movements were monitored by a Tobii eyetracker T120, with a sampling frequency of $60 \mathrm{~Hz}$. The stimuli were presented on a 17 -inch screen with a resolution of 1024 x 768 pixels. The distance between the participant's head and the screen was $600 \mathrm{~mm}$.

\section{Working Memory and Spatial Memory}

Reading span test (RST). The working memory task presented to the participants was a French version (Desmette et al., 1995; Morlaix \& Suchaut, 2015) of the traditional Daneman and Carpenter (1980) RST. This task, based on the second version, included true/false statements. The RST was translated from French to Spanish, the native language of the participants, and administered on a computer. The entire examination consists of a training block (three sequences of two extracts each) followed by 30 test phrases. The participants were required to read brief phrases and simultaneously memorize a number. Once each phrase was read, the participants had to decide if it was coherent or not before going on to the next phrase. The test phrases are divided into three blocks of 9, 12 and 20 phrases, comprising 12 sequences in total. After three sequences, one phrase is added so that sequences 1 to 3 (training level) have two phrases, sequences 4 to 6 (level 2) have three phrases, sequences 7 to 9 (level 3) include four phrases and sequences 10 to 12 (level 4) have five phrases. For the scoring of the test we took into account the total number of digits recalled in order to adopt a continuous measure as recommended by Friedman and Miyake (2005).

Corsi block-tapping test (CBT). All the material and the instructions were presented on a computer screen and each trial began with a 5-second count-down. The sequence of "blocks" was then displayed in random order. Once the sequence was finished, the participant repeated the order by clicking on the blocks with the mouse. The first sequences (training) had two items, and one item was added every three sequences until the limit of the participant's capacities was reached. To move on to the next level, one of the three presentations had to be successfully completed. The dependent variable was the total number of items accurately recalled in the correct serial position. Partial-credit unit scoring was used to grade the tests (Conway et al., 2005); specifically, a decimal score was assigned for tapping the blocks in the correct order and position at each level.

\section{Procedure}

Participants performed the RST and then, in another room equipped with an eye-tracker, performed the reading comprehension test (music and texts). The presentation of each set of stimuli was preceded by a calibration phase in which participants had to follow a red circle connecting nine points arranged on the screen. The calibration phase aims at correcting the variations that can influence the geometrical parameters necessary to assess gaze directions (Hammoud, 2008 in Holmqvist, et al., 2011). The two types of stimuli were counterbalanced.

Most previous research does not use time limits when stimuli are longer than 4 bars. However, there are some exceptions (Waters \& Underwood, 1998, Penttinen et al., 2013). In our study, participants were not under time limits for inspecting the stimuli and were instructed to keep their eyes on the screen. After reading the texts or scores, participants had to answer two questions on a sheet of paper. A new calibration phase preceded the presentation of each new stimulus. This procedure was repeated until 6 scores and 6 texts had been read. After completing both parts of the reading test, participants performed the CBT (see Figure 2). It should be noted that the CBT was applied at the end of the session because it has a shorter duration than RST, ensuring better attentional response at the end of the experiment.

Following the procedure of Servant and Baccino (1999), comprehension questions were designed to keep the attention of the musicians while permitting study of their oculomotor behaviour. In order to discourage reading patterns based on the surface structure of the text, one question was related to a local feature (i.e. peculiarities of the stimulus) and the other was related to a global feature (e.g. styles of music and text). For each question, participants had to choose between three possible answers. Examples of local questions are: How does the first musical phrase finish - Tonic, Subdominant or Dominant? Who is father Le Paige - a Missionary, a Traveller or an Architect? Examples of global questions are: What is the character of the piece - calm and restful, incisive or leg- 
gero? How would you describe the passage - Descriptive, Fantastic or Historical?

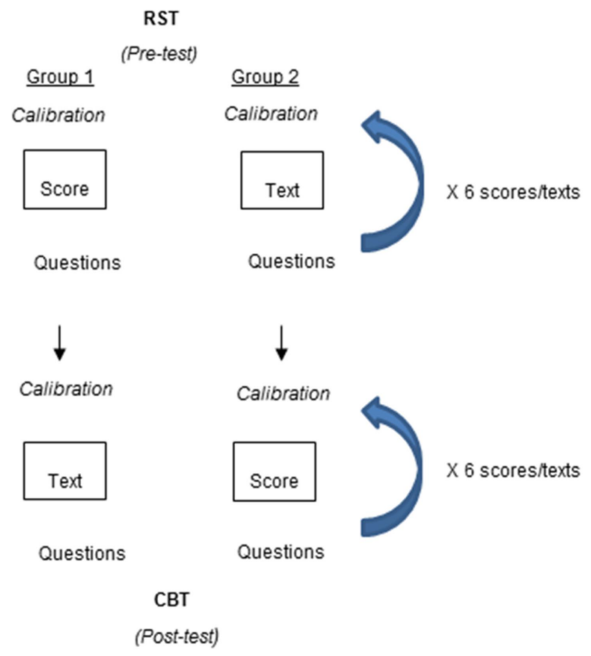

Figure 2. Experimental design. All participants followed the same counterbalanced protocol. As shown on the left side of the figure, group 1 began with text reading and group 2 began with score reading. The presentation of each stimulus was preceded by a calibration procedure. Once the reading finished participants had to answer comprehension questions. The arrow indicates that the procedure continued consistently for six trials; participants then switched materials, as indicated by the bottom of the figure. The memory tests were applied at the beginning (RST) and end (CBT) of the experiment.

\section{Data Analysis}

The algorithm used for data analysis comes from Tobii Studio software (Tobii standard filter). For texts and music, the same fixation filter with radius of 50 pixels was adopted in order to facilitate comparison between reading modalities allowing a balanced measure for both types of stimuli.

The dependent variables considered for statistical analysis were the number and duration of fixations, and the number of regressive fixations. The following independent variables were considered: (1) integrative controls (intra-sentence/phrase or inter-sentence/phrase; (2) reading stage (first pass or re-reading). We conducted Student's t-test to analyse simple effects for reading times, number of fixations and durations of fixations ( 6 scores +6 texts). Regressive fixations data from the se- lected stimuli were analysed in a repeated measures design.

Harmonic structure refers to the pitch dimension of music and the vertical organization of notes (chords); melodic structure defines the limits of phrases, for example, based on physical (i.e. space) or structural (i.e. harmonic) markers as noted by Sloboda (1977). Thus, in the present study sentences in text reading are equivalent to musical phrases, as the limits are defined by physical markers. In this work the unit of analysis in text reading is the sentence delimited by punctuation. In music, the unit is the musical semi-phrase. Therefore we will refer to phrase in the case of music, sentence in the case of text, and sentence/phrase when referring to both domains.

Criteria for structural analysis of stimuli. In order to analyse more deeply the role of regressive fixations in the reading comprehension process and compare the different reading strategies used by participants, one of each style of text and score were selected. The stimuli selected meet the following criteria: the highest percentage of correct answers in the comprehension questions (i.e. scores $70 \%$ and texts $80 \%$ ) and an average reading time that falls within the $95 \%$ confidence interval of the overall reading time distribution.

Intra-phrase regressive fixations occur within the same phrase/sentence, that is to say, in the case of texts between punctuation marks, and in the case of scores within semi-phrases. However, in the case of scores, semi-phrases in some pieces sometimes overlapped the next beat, meaning that not all semi-phrases finished exactly at the bar line (i.e. elision). In these cases, the boundary established for analysis was the final beat of the musical semi-phrase.

Reading stages (first pass and re-reading measurements). Earlier stages of reading can be studied with first pass measurements (Clifton, Staub \& Rayner, 2007), while the later stages of reading can be assessed by analysing second pass measures intended to integrate and store information (Servant \& Baccino, 1999) during reading. In silent reading it is possible to study both reading stages more deeply. For texts, the first pass corresponds to the initial set of eye fixations within the same sentence before moving on to the next sentence. In the case of music, the first pass comprises a full bar considering that there must be at least one fixation (in beats) per unit in each stave (i.e. treble and bass clef). Re-reading meas- 
urements were defined as all fixations on information subsequent to the first pass of information. When a region was not re-read, it was not considered. The criteria for the analysis of inter and intra-sentence/phrase limits in texts (punctuation marks) and scores were the same as those used for music scores and mentioned in the preceding section.

In order to account for cognitive processes operating at different stages in reading, we analysed the first pass and the re-reading information for the selected stimuli. Furthermore the intra and inter-sentence/phrase level led us to compare local and global controls during the integration of musical and verbal information. Data was analysed using the MATLAB programming which allowed us to study in greater detail the intra and intersentence/phrase eye movement patterns. For this reason we do not consider defining areas of interest (AOI) in stimuli to be relevant.

\section{Results}

Two analyses were performed. The first analysis examined overall data (six texts and six scores). The second analysis was performed using data from four selected stimuli, one for each type of text (informative and literary) and musical style (tonal and contemporary).

\section{Analysis 1, Overall Data}

To analyse the simple effects between reading texts or scores (reading modalities and styles), mean comparisons (Student's t-test) were performed including the reading times and the number and duration of fixations.

\section{Reading Times}

The reading times of the musical pieces $(M=68.09$ $\mathrm{ms}, S D=16.76[56.10,80.08])$ and the texts $(M=64.55$ $\mathrm{ms}, S D=17.04[52.36,76.75])$ did not differ significantly $(t(9)=0.641, p=.54, d=0.209,95 \%$ CI $[-16.02,8.95]$, $r=.10$ ), nor were significant differences in reading time found between musical styles $(t(9)=0.323, p=.75, d=$ $0.018,95 \%$ CI $[-42.85,57.12], r=.009)$ or text styles $(t(9)=1.47, p=.18, d=0.251,95 \%$ CI [-11.76, 2.51], $r$ $=.12$ ). These results suggest that the time spent in silent reading of texts and scores was relatively equivalent, which supports the closeness between the two tasks.

\section{Eye Fixations}

Number of fixations. Participants performed on average half the number of fixations when reading music $(M$ $=80.5, S D=31.39,95 \%$ CI $[58.05,102.95])$ as compared with reading text $(M=170.68, S D=39.79[142.22$, 199.15]). Thus, differences between reading modalities were significant $(t(9)=8.38, p<.001, d=2.516,95 \% \mathrm{CI}$ $[65.84,114.53], r=.78)$. Although the number of fixations in tonal music was greater than in contemporary music, the difference did not quite achieve significance. Moreover, no significant differences were found between informative and literary texts, representing a possible explanation for the absence of difference in reading times (see Table 1). Significant correlations between the overall reading time and the overall number of eye fixations $(\mathrm{r}(8)$ $=.79, \mathrm{p}=.007)$ were observed which is in line with the literature (Kinsler \& Carpenter, 1995).

Table 1. Average number and duration (ms) of fixations, and comparisons between music and text styles, using paired Student's t- test.

\begin{tabular}{|c|c|c|c|c|c|c|c|c|c|}
\hline \multirow[b]{2}{*}{ Variable } & \multicolumn{2}{|c|}{ Tonal } & \multicolumn{2}{|c|}{ Contemporary } & \multirow[b]{2}{*}{$t(9)$} & \multirow[b]{2}{*}{$p$} & \multicolumn{2}{|c|}{$95 \% \mathrm{CI}$} & \multirow{2}{*}{$\begin{array}{c}\text { Cohen's } \\
d\end{array}$} \\
\hline & $M$ & $S D$ & $M$ & $S D$ & & & $L L$ & $U L$ & \\
\hline Number & 91.77 & 40.09 & 69.23 & 32.38 & 1.93 & .086 & -3.95 & 49.02 & 0.618 \\
\hline \multirow[t]{3}{*}{ Duration } & 616.92 & 66.88 & 561.01 & 85.79 & 1.75 & .12 & -16.56 & 128.37 & 0.727 \\
\hline & \multicolumn{2}{|c|}{ Informative } & \multicolumn{2}{|c|}{ Literary } & \multirow[b]{2}{*}{$t(9)$} & \multirow[b]{2}{*}{$p$} & \multicolumn{2}{|c|}{$95 \% \mathrm{CI}$} & Cohen's \\
\hline & $M$ & $S D$ & $M$ & $S D$ & & & $L L$ & $U L$ & $d$ \\
\hline Number & 174.70 & 43.09 & 162.65 & 40.10 & 1.30 & .26 & -8.90 & 33 & 0.289 \\
\hline Duration & 310.73 & 33.91 & 337.45 & 68.33 & 2.05 & .07 & -2.73 & 56.15 & 0.495 \\
\hline
\end{tabular}


Duration of fixations. We observed significant differences $(t(9)=14.38, \quad p<.001, d=3.306,95 \%$ CI [226.11, 301.04 ], $r=.87$ ) between texts and scores, with longer fixation durations for scores $(M=586.52 \mathrm{~ms}, S D$ $=87.95[554.56,619.08])$ than for texts $(M=319.16 \mathrm{~ms}$, $S D=53.44$ [301.4, 338.12]). Regarding the music and text styles, no significant difference was observed either between tonal and contemporary music, or between informative and literary styles. On average however, fixation length was higher for tonal music and for literary texts.

\section{Analysis 2, Selected Stimuli}

A repeated measures ANOVA for the number of regressive fixations with processing level (i.e. intersentence/phrase or intra-sentence/phrase) and reading stage (i.e. first pass or re-reading) as factors was conducted.

Fixation patterns. Broadly speaking, the number of regressive fixations is higher for music $(M=57.3, S D=$ $18.11[44.34,70.26])$ than for texts $(M=52, S D=20.49$ $[37.34,66.66])$, although the difference was not significant $\left(F(1,36)=0.97, p=0.33, \eta_{\mathrm{p}}{ }^{2}=.03\right)$. In contrast, significant differences were observed between inter and intra-sentence/phrase processing levels $(F(1,36)=20.30$, $\left.p<.001, \eta_{\mathrm{p}}{ }^{2}=.36\right)$ with further processing intrasentence/phrase $(M=37.15, S D=11.56$ [22.88, 45.42]) than with inter-sentence/phrase processing level $(M=$ 17.30, $S D=6.14$ [12.91, 21.69]). An interaction between the type of reading (texts/scores) and the processing level $\left(F(1,36)=30.58, p=.001, \eta_{\mathrm{p}}{ }^{2}=.46\right)$ indicates that in music reading, inter-phrase regressive fixations are more frequent and there was less variation between inter and intra-phrase levels. By contrast, text reading is characterized by higher intra-phrase processing levels.

Planned contrasts show significant differences between the styles of music and texts with more intrasentence/phrase regressive fixations in contemporary music in comparison with tonal music $(F(1,36)=8.25, p$ $\left.=.006, \eta_{\mathrm{p}}{ }^{2}=.19\right)$ and in informative text in comparison with literary text $\left(F(1,36)=44.36, p<.001, \eta_{\mathrm{p}}{ }^{2}=.55\right)$. Regarding inter-sentence/phrase regressive fixations, we found differences between music styles $(F(1,36)=4.60$, $p=.002, \eta_{\mathrm{p}}{ }^{2}=.11$ ) but not between text styles (see Figure 3$)$.

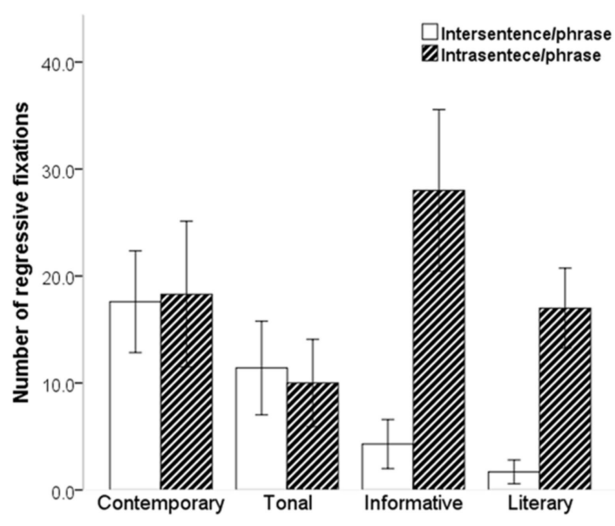

Figure 3. Number of intra-sentence/phrase and intersentence/phrase regressive fixations in selected stimuli: texts (informative and literary) and music (contemporary, tonal).

\section{First Pass and Re-Reading}

During the first pass (sentences in texts and semiphrases in scores), the number of regressive fixations was significantly lower $\left(F(1,36)=23.32, p<.001, \eta_{\mathrm{p}}{ }^{2}=.39\right)$ in the scores $(M=14.3, S D=3.8[11.58,17.02])$ than in the texts $(M=36.1, S D=12.95[26.83,45.39])$.

Globally, we observed a decrease in intra-sentence regressive fixations in texts and an increase in interphrase regressive fixations in scores between the two reading stages analysed. Planned contrast showed that the average number of regressive fixations during re-reading increased significantly at intra and inter-phrase level in contemporary music $(F(1,36)=17.46, p<.001,=.33$; $\left(F(1,36)=16.46, p<.001, \eta_{\mathrm{p}}{ }^{2}=.31\right.$, respectively $)$, but only at inter-phrase level in tonal music $(F(1,36)=6.19$, $\left.p=.017, \eta_{\mathrm{p}}{ }^{2}=.15\right)$ in contrast with the intra-phrase level where differences between reading phases were not significant $\left(F(1,36)=2.34, p=.13, \eta_{\mathrm{p}}{ }^{2}=.06\right)$. In text reading, regressive fixations decreased at intra-sentence level in both informative and literary styles $(F(1,36)=22.55, p$ $<.001, \eta_{\mathrm{p}}{ }^{2}=.39 ; F(1,36)=133.24, p<.001, \eta_{\mathrm{p}}{ }^{2}=.79$, respectively) and increased at inter-sentence level but only in literary style $F(1,36)=4.17, p=.048, \eta_{\mathrm{p}}{ }^{2}=.10$ ). In informative text this increase was not statistically significant $\left(F(1,36)=0.44, p=.51, \eta_{\mathrm{p}}{ }^{2}=.01\right)$.

In summary, it should be noted that during text reading, after the first pass, intra-sentence controls decrease significantly. This suggests that the integration of infor- 
mation in text reading is performed sequentially at intrasentence level, with a tendency to increase intersentence/phrase controls during the re-reading stage. On the other hand, music reading is characterized by deeper and repetitive intra-phrase controls. Thus, the first reading of a semi-phrase would not be enough to obtain the necessary information for global integration. However, it should be noted that piano notation is characterized by organization into vertical units (chords) and two staves. This implies a zigzag eye movement trajectory, described by Weaver (1934) which could well explain the occurrence of intra-phrase controls.

\section{Individual Strategies}

From analysis of individual strategies, and comparing this information with the results previously presented, we conclude that there are no overlapping reading patterns in the two domains. We can therefore say that reading patterns are directly related to the specific music style or type of text. However, two main reading strategies can be assumed, one sequential and the other selective. Neither strategy can be associated with a particular style of music or type of text, as previously stated. More specific individual profiles are difficult to classify. For example, some musicians did not re-read most of the stimuli but did reread one in particular. Others employed few integration controls and used a selective but non-integrative strategy in contrast with those who utilized a selective and integrative strategy.

\section{Memory Tests}

We found significant correlations between the CBT and the number of digits recalled in RST $(r(8)=.76 p<$ $0.01)$. This suggests certain independence between visual-perceptual and analytical-comprehensive information processing.

With the exception of the correlations between memory tasks and fixation duration in text reading (i.e. RST reaction times with fixation duration, $r=.66, p=$ .038), the RST was mostly associated with variables accounted for by contemporary music. These variables included, in the storage component of the RST, the average number of fixations in all musical pieces $(r=-.86, p$ $<.001)$ and fixation duration in contemporary music $(r=$ $-.56, p=.09$ ). In the processing component of the RTS, these variables concern the reading time in contemporary music $(r=-.67, p=.032)$ and the number of hours of piano practice $(r=.65, p=.044)$.
In parallel, a link between spatial memory and regressive inter-sentence/phrase fixations in literary texts $(r=$ $.66, p=.032)$ and contemporary music $(r=.70, p=.025)$ suggests that some resources may be shared between the two domains.

\section{Discussion}

The present study examined oculomotor behaviour in a silent reading task that differed from other tasks such as reading music for performance or simply reading aloud (Caltelhano \& Rayner, 2008). We studied how structural units defined by physical and structural markers can determine changes in eye movement patterns between different styles of music (tonal and contemporary) and text types (informative and literary). These comparisons are based on the reasoning that: (1) there are no differences in the number and duration of eye fixations nor in reading times between styles of music and texts; (2) small-scale structures of the stimuli (sentences and musical semiphrases) are equivalent in number; and (3) the amount of information in each stimulus seems to be compensated by the number/duration ratio of eye fixations, especially between reading types (i.e. scores and texts).

\section{Task Constraints}

Globally, we found some differences between reading modalities: eye fixations were more numerous in text reading, and fewer but longer in music reading. These results are corroborated in the literature (Rayner, 1998; Baccino, 2004; Ahken, Comeau, Hébert, \& Balasubramaniam, 2012). In particular, the reading of tonal music and literary texts was associated with longer eye fixations, while reading of informative texts and contemporary music was associated with a greater number of regressive fixations. As was expected we found a higher number of regressive fixations in the scores than in the texts. We propose that there is a certain independence between these two variables (duration of fixations and number of regressive fixations) to account for the relation between musical facts and eye-movement patterns. However, neither the previously discussed results nor knowledge from previous studies lead us to the conclusion that there is equivalence between a particular musical stimulus (tonal or contemporary) and a verbal text (literary or informative). 


\section{Reading Stages and Reading Effectiveness}

We found that the efficiency of text reading as compared to music reading is not easy to prove if one considers only the earlier stages of the reading process. In fact, the number of inter-phrase regressive fixations is higher for music while intra-phrase regressive fixations are more associated with text reading (with a significant decrease during re-reading in both text types).

We observed a tendency to increase the number of regressive fixations during the re-reading stage at an interphrase level, however this increase was not significant in text reading. An inverse relationship was observed in intra-phrase fixations, illustrated first by a tendency to increase the number of regressive fixations during the rereading stage in the case of contemporary music and secondly by a decrease in intra-sentence/phrase fixations in both styles of text. This suggests, firstly, that the effectiveness of the local and global integrative reading mechanisms depends mainly on the style of music and text; and secondly that reading strategies based on the informational structure of the stimuli (Landragin, 2004), linked with inter-phrase regressive fixations, can be used to verify the adequacy of certain global elements in the local context (i.e. at intra-phrase level).

Concerning total reading time, the association between informative and literary texts suggests that the speed of information integration responds to the mobilization of common mechanisms in text reading. This is plausible because the amount of information in the different stimuli appears to be comparable since both had a similar number of words. Although there is no a priori evidence to confirm that literary texts contain less information than informative texts (see Table A2), the reading of informative texts does not require additional regressive fixations in the re-reading process. Instead, the ideas would be extracted sequentially through inter-sentence integration and with the mobilisation of spatial memory coding (see Baccino \& Pynte, 1994; see also Kennedy, Brooks, Flynn, \& Prophet, 2003). Additionally, correlations between the overall reading time and the overall number of eye fixations are in line with the literature (Kinsler \& Carpenter, 1995).

\section{Reading Patterns and Reading Strategies}

Music reading patterns vary according to the music style. This suggests that the integration of information in the two styles occurs at different levels. In the case of contemporary music, a tendency for inter-phrase and intra-phrase controls was observed. Cave et al. (2008) suggest that if the number of saccades performed between complex visual patterns is equal to the number of saccades within each pattern, this would go against a holistic strategy for stimulus comparison (p. 154). It seems then that reading contemporary music induces the development of less sequential inspection strategies. These patterns, unlike tonal music, may be determined according to the melodic shape of musical motifs (or musical texture from a historical counterpoint perspective) rather than the sequential development of musical phrases.

In summary, the reading of contemporary music is characterized by a less sequential path for musical information integration, while the reading of tonal music is characterized by a more sequential path for musical information integration determined by harmonic tonal relationships.

These differences are confirmed by analysis of participants' individual reading strategies. Like previous studies (Penttinen, et al., 2013), we found integrative and analytical strategies for reading music and texts. However, individual strategies were modified depending on the style of music and type of text, suggesting the mobilisation of domain-specific skills. In this regard we provide evidence of a link between visuospatial capacities and the reading of contemporary music. Further research is required to address the link between cognitive skills and the reading strategies of different musical styles.

\section{Cognitive Skills}

In literary texts, there were a greater number of intrasentence regressive fixations, however, almost no rereading process. This suggests that there are significant differences with respect to the integrative mechanism between texts and scores. Due to the absence of significant correlations between the memory tests and text reading-related variables, it is not possible to determine whether these differences depend on storage or verbal processing capabilities, or even short-term spatial memory.

Our results suggest that spatial memory is associated with eye movement patterns according to the style. This arises from the basis of the correlations observed between the average reading time for contemporary music and the results in the CBT. Furthermore, the increased number of inter-phrase regressive fixations in reading contemporary 
music could reflect information processing based on visual and perceptual aspects of the stimulus, related to the capacities measured by the CBT. In fact, the mobilization of spatial memory capacities seems to facilitate the processing of information in contemporary music reading, thus facilitating global comparisons between musical motifs (correlations between the CBT and inter-phrase regressive fixations). This suggests that analytical and visual-perceptual features are relatively independent in silent music reading. Moreover, in the case of literary texts, inter-sentence processing is associated with shortterm spatial memory, suggesting a spatial coding of verbal information (Baccino \& Pynte, 1994).

From these results and the observation of individuals' inspection strategies we can suggest that musicians adopt different strategies according to their cognitive skills, possibly offset by a more analytical reading. This could be considered if we assume that the CBT involves executive functions (Klauer \& Zhao, 2004; Miyake, Friedman, Rettinger, Shah, \& Hegarty, 2001; Vandierendonck, Kemps, Fastame, \& Szmalec, 2004; Thompson et al., 2006).

The fact that the correlations between the RST and the set of all the variables studied were found mainly in contemporary music reading suggests that tonal music is not strongly dependent on verbal or spatial memory capabilities. On the other hand, this could indicate the implementation of different strategies during the reading of contemporary music. For example, information from the analysis of musical harmony could temporarily be coded verbally. The coding assigned to each unit would facilitate comparison of different musical motifs (e.g. descendent motifs). This would mean, for example, that with more efficient processing of verbal information we should find shorter eye fixations in the reading of contemporary music.

The limitations of this study mainly concern the adoption of certain methodological commitments that allowed us to compare the two domains. For example, the absence of a time limit for inspection of the stimuli, as well as the definition of the comparison units and the choice of eye fixation filters.

The results of the present study could have an impact on clarifying the relationship between music and verbal language as well as in the definition of units of comparison between the two domains. It could also contribute to the definition of reading comprehension strategies and their relationship to cognitive abilities and skills developed by musicians.

\section{Conclusion}

This study reports certain commonalities and differences between silent reading of texts and scores. Eye movement information reflects different strategies used by pianists for processing verbal and musical information, which are manifested in differences in the mechanisms underlying information intake (number of fixations) and information integration (duration of fixations and number of regressive fixations). Our results are consistent with findings of Sloboda (1977) on the relevance of the sentence/phrase as a unit of comparison between music and text reading. Moreover, as we expected, structural units defined by physical and structural markers elicit different eye movement patterns according to the musical style and the type of text. This is observed in both local and global integrative controls as in the different reading stages. Moreover, reading strategies differ between participants and from a qualitative point of view, no cross-patterns are observed between styles and reading modalities. All this suggests that, despite the similarity in overall eye movement patterns in music and text, the underlying processes and the required skills are different, although this does not rule out the possibility of resourcesharing between the two domains.

\section{Acknowledgments}

The authors acknowledge the assistance of Kenya Godoy for her support in the development of this research and in encouraging piano students to participate in this study.

The authors declare that there is no conflict of interest regarding the publication of this paper.

\section{Funding}

This research was supported by a Doctoral Fellowship Award from Becas Chile-CONICYT (grant 72100347). Funding from PIA-CONICYT Basal Funds for Centers of Excellence Project BF0003 is gratefully acknowledged. 
Journal of Eye Movement Research

$9(7): 2,1-17$
Cara, M. A., \& Gómez Vera, G. (2016)

Silent reading of music and texts

\section{References}

Ahken, S., Comeau, G., Hébert, S., \& Balasubramaniam, R. (2012). Eye movement patterns during the processing of musical and linguistic syntactic incongruities. Psychomusicology: Music, Mind and Brain, 22(1), 18-25. http://dx.doi.org/10.1037/a0026751

Arbib, M. A. (2013). Five terms in search of a synthesis. In M. A, Arbib (Ed.), Language, music, and the brain: A mysterious relationship (pp. 3-44). Cambridge: MIT Press.

Arom, S. (2000). Prolegomena to a biomusicology. In N. Wallin, B. Merker, \& S. Brown (Eds.), The origins of music (pp. 27-30). Cambridge: A Bradford Book: MIT press.

Asano R., \& Boeckx C. (2015). Syntax in language and music: what is the right level of comparison? Frontiers in Psychology, 6, 942. http://dx.doi.org/10.3389/fpsyg.2015.00942

Ashby, J., \& Clifton, C. (2005). The prosodic property of lexical stress affects eye movements during silent reading. Cognition, 96(3), B89-B100. http://dx.doi.org/10.1016/j.cognition.2004.12.006

Baccino, T. (2004). La lecture électronique [Electronic reading]. Grenoble: Presses Universitaires de Grenoble.

Baccino, T. \& Pynte, J. (1994). Spatial coding and discourse models during text reading. Language and Cognitive Processes, 9(2), 143-155.

Baddeley, A. D. (1990). Human memory: Theory and practice. London: Lawrence Erlbaum Associates.

Baddeley A. D. (2003). Working memory: Looking back and looking forward. Nature Reviews Neuroscience, 4, 829-839. http://dx.doi.org/10.1038/nrn1201

Bigand, E., Lalitte, P., Lerdahl, L., Boucheix, J.-M., Gérard, Y., \& Pozzo, T. (2010). Looking into the eyes of a conductor performing Lerdahl's "Time after Time". Musica Scientice. 275-294. http://dx.doi.org/10.1177/10298649100140S215

Botto, C. (1965) (ed.), El pianista chileno [The chilean pianist], (Vol. I), serie D Nº1 (Facultad de Ciencias y Artes Musicales y Ediciones del IEM de la Universidad de Chile).

Burman, D. D., \& Booth, J. R. (2009). Music rehearsal increases the perceptual span for notation. Music Per- ception, 26(4), 303-320.

http://dx.doi.org/10.1525/mp.2009.26.4.303

Byrne, B. (2005). Theories of learning to read. In M. J. Snowling, C. Hulme (Eds.), The Science of Reading: A Handbook. (pp. 104-119). London: Blackwell.

Castelhano, M. S., \& Rayner, K. (2008). Eye movements during reading, visual search, scene perception: an overview. In K. Rayner, D. Shen, X. Bai, \& G. Yan (Eds.), Cognitive and cultural influences on eye movements (pp. 3-33). Tianjin: Tianjin People's Press/Hovee.

Cave, K. R., Cohen, A. L., Rotello, C. M., McCaffrey, A., Ross, M. G., Zeng, M.,...Chang, K. (2008). Using eye movements to understand complex visual comparisons. In K. Rayner, D. Shen, X. Bai, \& G. Yan (Eds.), Cognitive and cultural influences on eye movements (pp. 141-156). Tianjin: Tianjin People's Press/Hovee.

Clifton, C., Staub, A., \& Rayner, K. (2007). Eye movements in reading words and sentences. In R.P.G. van Gompel, M.H. Fischer, W.S. Murray, \& R.L. Hill (Eds.), Eye movements: $A$ window on mind and brain (pp. 341-371). New York: Elsevier.

Conway, A. R. A., Kane, M. J., Bunting, M. F., Hambrick, D. Z., Wilhelm, O., Engle, R. W. (2005). Working memory span tasks: A methodological review and user's guide. Psychonomic Bulletin and Review, 12,769-786. http://dx.doi.org/10.3758/BF03196772

Daneman, M., \& Carpenter, P. A. (1980). Individual differences in working memory and reading. Journal of Verbal Learning and Verbal Behavior, 19, 450466. http://dx.doi.org/10.1016/S0022-5371(80)90312$\underline{6}$

Desmette, D., M. Hupet, M-A. Schelstraete, \& M. Van der Linden. (1995). Adaptation en langue française du 'reading span test' de Daneman et Carpenter [French adaption of Daneman \& Carpenter' reading span test]. L'annee Psychologique 95(3), 459-482. http://dx.doi.org/10.3406/psy.1995.28842

Drai-Zerbib, V., \& Baccino., T. (2005). L'expertise dans la lecture musicale: integration intermodale [Expertise in music reading: Intermodal integration]. L'Année Psychologique, 105, 387-422.

Drai-Zerbib, V., \& Baccino, T. (2014). The effect of expertise in music reading: cross-modal competence. 
Journal of Eye Movement Research 9(7):2, 1-17

Journal of Eye Movement Research, 6(5), 1-10. http://dx.doi.org/10.16910/jemr.6.5.5

Drai-Zerbib, V., Baccino, T., \& Bigand, E. (2012). Sightreading expertise: Cross-modality integration investigated using eye-tracking. Psychology of Music 40(2), 216-235.

http://dx.doi.org/10.1177/0305735610394710

Ehrlich, M. F., Brébion, J., \& Tardieu, H. (1994). Working memory capacity and reading comprehension in young and older adults. Psychological Research, 56, 110-115. http://dx.doi.org/10.1007/BF00419718

Fayol, M., David, J., Dubois, D., \& Rémond, M. (2000). Maîtriser la lecture. Poursuivre l'apprentissage de la lecture de 8 à 11 ans [Mastering the reading. Continue learning reading from 8 to 11 years]. Paris : Odile Jacob.

Gilman, E., \& Underwood, G. (2003). The perceptual span during music reading. In J. Hyönä, R. Radach and H. Deubel (Eds.), The mind's eye: cognitive and applied aspects of eye movement research (pp. 117192). New-York: North-Holland.

Goldberg, J. H., \& Kotval, X. P. (1999). Computer interface evaluation using eye movements: methods and constructs. International Journal of Industrial Ergonomics, 24(6), 631-645. http://dx.doi.org/10.1016/S0169-8141(98)00068-7

Goldberg, J. H., \& Schryver, J. C. (1995). Eye-gazecontingent control of the computer interface: Methodology and example for zoom detection. Behavior Research Methods, Instruments and Computers, 27(3), 338-350. http://dx.doi.org/10.3758/BF03200428

Goolsby, T. W. (1994a). Eye movement in music reading: Effects of reading ability, notational complexity, and encounters. Music Perception, 12(1), 77-96. http://dx.doi.org/10.2307/40285756

Goolsby, T. W. (1994b). Profiles of processing: Eye movements during sight-reading, Music Perception, 12(1), 97-123. http://dx.doi.org/10.2307/40285757

Graesser, A. C., McNamara, D. S., \& Louwerse, M. M. (2003). What do readers need to learn in order to process coherence relations in narrative and expository text? In A. P. Sweet \& C. Snow (Eds.), Rethinking reading comprehension (pp. 82-98). New York: Guilford.
Cara, M. A., \& Gómez Vera, G. (2016)

Silent reading of music and texts
Hammoud, R. I. (2008). Passive eye monitoring: Algorithms, applications and experiments. Ney York: Springer-Verlag.

Hébert, S., \& Cuddy, L. L. (2006). Music-reading deficiencies and the brain. Advances in Cognitive Psychology, 2, 199-206. http://dx.doi.org/10.2478/v10053-008-0055-7

Hochberg, J. (1976). Toward a speech-plan eyemovement model of reading. In R. A. Monty \& J. W. Senders (Eds.), Eye movements and psychological processes. Hillsdale, NJ: Erl- baum.

Holmqvist, K., Holšánová, J., Barthelson, M., \& Lundqvist, D. (2003). Reading or scanning? A study of newspaper and net paper reading. In J. Hyönä, R. Radach, J., H. Deubel (Eds.), The mind's eye. Cognitive and applied aspects of eye movement research (pp. 657-670). Amsterdam: North Holland.

Holmqvist, K., Nyström, M., Andersson, R., Dewhurst, R., Jarodzka, H., \& Van de Weijer, J. (2011). Eye tracking: A comprehensive guide to methods and measures. Oxford: Oxford University Press.

Hutzler, F., \& Wimmer, H. (2004). Eye movements of dyslexic children when reading in a regular orthography. Brain and Language, 89, 235-242. http://dx.doi.org/10.1016/S0093-934X(03)00401-2

Hyönä J. (1995). An eye movement analysis of topic-shift effect during repeated reading. Journal of Experimental Psychology: Learning, Memory and Cognition, 21, 1365-1373. http://dx.doi.org/10.1037/02787393.21.5.A

Iser, W. (1997). L'acte de lecture: théorie de l'effet esthétique [The act of reading: Theory of aesthetic effect]. Bruxelles: Pierre Mardaga.

Johansson, R., Holmqvist, K., Mossberg, F., \& Lindgren, M. (2012). Eye movements and reading comprehension while listening to preferred and non-preferred study music. Psychology of Music, 40(3), 339-356. http://dx.doi.org/10.1177/0305735610387777

Kennedy, A., Brooks, R., Flynn, L., \& Prophet, C. (2003). The reader's spatial code. In J. Hyona, R. Radach, \& H. Deubel (Eds.), The mind's eye: Cognitive and applied aspects of eye movement research (pp. 193-212). Amsterdam: North Holland.

Koelsch, S. (2012). Brain and music. Oxford: John Wiley and Sons, Ltd. 
Journal of Eye Movement Research

9(7):2, 1-17

Koelsch, S. , Kasper, E., Sammler, D, , Schulze, K., Gunter, T. \& Friederici, A. D. (2004). Music, language and meaning: brain signatures of semantic processing. Nature Neuroscience, 7, 302-307.

http://dx.doi.org/10.1038/nn1197

Just, M. A., \& Carpenter, P. A. (1980). A theory of reading: From eye fixation to comprehension. Psychological Review, 87, 329-354. http://dx.doi.org/10.1037/0033-295X.87.4.329

Just, M. A., \& Carpenter, P. A. (1987). The psychology of reading and language comprehension. Boston: Allyn and Bacon, Inc.

Kane, M. J., Hambrick, D. Z., Tuholski, S. W., Wilhelm, O., Payne, T. W., \& Engle, R. W. (2004). The generality of working memory capacity: A latent-variable approach to verbal and visuospatial memory span and reasoning. Journal of Experimental Psychology: General, 133(2), 189-217. http://dx.doi.org/10.1037/0096$\underline{3445.133 .2 .189}$

Kinsler, V., \& Carpenter, R. H. S. (1995). Saccadic eye movements while reading music. Vision Research, 35, 1447-1458.http://dx.doi.org/10.1016/00426989(95)98724-N

Klauer, K. C., \& Zhao, Z. (2004). Double dissociations in visual and spatial short-term memory. Journal of Experimental Psychology: General, 133, 355-381. http://dx.doi.org/10.1037/0096-3445.133.3.355

Landragin F. (2004). Saillance physique et saillance cognitive [Physical and cognitive salience]. Cognition, Représentation, Langage (CORELA) 2(2): http://corela.revues.org/603

Lévy-Schœn A. (1988). Les mouvements des yeux comme indicateurs des processus cognitifs. In J. P. Caverni, C. Bastien, P. Mendelsohn, \& G. Tiberghien (Eds.), Psychologie cognitive, modèles et méthodes (pp. 329-347). Grenoble: Presses Universitaires de Grenoble.

Madell, J., \& Hébert, S. (2008). Eye movements and music reading: Where do we look next? Music Perception, 26(2), 157-170.

http://dx.doi.org/10.1525/mp.2008.26.2.157

Miyake, A., Friedman, N. P., Rettinger, D. A., Shah, P., \& Hegarty, M. (2001). How are visuospatial working memory, executive functioning, and spatial abilities related? A latent-variable analysis. Journal of Experimental Psychology: General, 130, 621-640. http://dx.doi.org/10.1037/0096-3445.130.4.621
Cara, M. A., \& Gómez Vera, G. (2016) Silent reading of music and texts

Patel, A. D. (2008). Music, language, and the brain. Oxford, UK: Oxford University Press.

Penttinen, M., Huovinen, E., \& Ylitalo, A.-K. (2013). Silent music reading: Amateur musicians' visual processing and descriptive skill. Musicae Scientiae, $17(2), 198-216$. http://dx.doi.org/doi:10.1177/1029864912474288

Penttinen, M., Huovinen, E., \& Ylitalo, A. K. (2015). Reading ahead: Adult music students' eye movements in temporally controlled performances of a children's song. International Journal of Music Education, 33(1), 36-50. http://dx.doi.org/10.1177/0255761413515813

Polanka, M. (1995). Research note: Factors affecting eye movements during the reading of short melodies. Psychology of Music, 23(2), 177-183. http://dx.doi.org/10.1177/0305735695232005

Rayner, K. (1998). Eye movements in reading and information processing: 20 years of research. Psychological Bulletin, 124(3), 372-422. http://dx.doi.org/10.1037/0033-2909.124.3.372

Rayner, K., Chace, K., Slattery, T., \& Ashby, J. (2006). Eye movements as reflections of comprehension processes in reading. Scientific Studies of Reading, 10(3), 241-255. $\underline{\text { http://dx.doi.org/10.1207/s1532799xssr1003 3 }}$

Rayner, K., \& Pollatsek, A. (1997). Eye movements, the eye-hand span, and the perceptual span during sightreading of music. Current Directions in Psychological Science, 6, 49-53. http://dx.doi.org/10.1111/1467$\underline{8721 . e p 11512647}$

Seyfert, U., Verschure, P. F.M., Arbib, M. A., Cohen, A. J., Fogassi, L., Fritz, T.,... \& Rickard, N. (2013). Semantic of internal and external words. In M. A, Arbib (Ed.), Language, music, and the brain: $A$ mysterious relationship (pp. 203-229). Cambridge: MIT Press.

Sergent, J., Zuck, E., Terriah, S., \& MacDonald, B. (1992). Distributed neural network underlying musical sight-reading and keyboard performance. Science, 257, 106-109. http://dx.doi.org/10.1126/science.1621084

Servant, I., \& Baccino, T. (1999). Lire Beethoven : une étude exploratoire des mouvements des yeux [Reading Beethoven: An exploratory study of eye move- 
Journal of Eye Movement Research

9(7):2, 1-17

ment]. Musicae Scientiae, 3(1), 67-94. http://dx.doi.org/10.1177/102986499900300104

Sloboda, J. A. (1974). The eye-hand span-an approach to the study of sight-reading. Psychology of Music, 2(2), 4-10. http://dx.doi.org/10.1177/030573567422001

Sloboda, J. A. (1977). Phrase units as determinants of visual processing in music reading. British journal of Psychology, 68, 117-124. http://dx.doi.org/10.1111/j.2044-8295.1977.tb01566.x

Sloboda, J. A. (1984). Experimental studies of music reading: A review. Music Perception, 2, 222-236. http://dx.doi.org/10.2307/40285292

Stewart, L., Henson, R., Kampe, K., Walsh, V., Turner, R., \& Frith, U. (2003). Brain changes after learning to read and play music. NeuroImage 20(1), 71-83. http://dx.doi.org/10.1016/S1053-8119(03)00248-9

Thompson, J. M., Hamilton, C. J., Gray, J. M., Quinn, J. G., Mackin, P., Young, A. H., \& Ferrier, I. N. (2006). Executive and visuospatial sketchpad resources in euthymic bipolar disorder: implications for visuospatial working memory architecture. Memory, 14, 437-451. http://dx.doi.org/10.1080/09658210500464293

Thompson-Schill, S., Hagoort, P., Ford Dominey, P., Honing, H., Koelsch, S., Ladd, D. R.,... \& Steedman, M. (2013). Multiple levels of structure in language and Music. In M. A, Arbib (Ed.), Language, music, and the brain: A mysterious relationship. (pp.289306). Cambridge: MIT Press.

Vandierendonck, A., Kemps, E., Fastame, M. C., \& Szmalec, A. (2004). Working memory components of the Corsi block task. British Journal of Psychology, 95, 57-79. http://dx.doi.org/10.1348/000712604322779460

Van Dijk, T. A. \& Kintsch, W. (1983). Strategies of discourse comprehension. New York: Academic Press.

Vitu, F. (2005). Visual extraction processes and regressive saccades in reading. In Underwood, G. (ed.), Cognitive processes in eye guidance. Oxford: Oxford University Press.

Waters, A. J., \& Underwood, G. (1998). Eye movements in a simple music reading task : A study of expert and novice musicians. Psychology of Music, 26(1), 46-60. http://dx.doi.org/10.1177/0305735698261005

Waters, A. J., Underwood, G., \& Findlay, J. M. (1997). Studying expertise in music reading: Use of a pattern-
Cara, M. A., \& Gómez Vera, G. (2016)

Silent reading of music and texts

matching paradigm. Perception \& Psychophysics, 59(4), 477-488.

http://dx.doi.org/10.3758/BF03211857

Weaver, H. A. (1943). A survey of visual processes in reading differently constructed musical selections. Psychological monographs, 55(1), 1-30.

Wolf, T. (1976). A cognitive model of musical sightreading. Journal of Psycholinguistic Research, 5(2), 143-171.

Wright, B., \& Stenner, A. (1998, June). Readability and Reading Ability. Paper presented to the Australian Council on Education Research.

Wurtz, P., Mueri, R. \& Wiesendanger, M. (2009). Sightreading of violinists: Eye movements anticipate the musical flow. Experimental Brain Research, 194(3), 445-450. http://dx.doi.org/10.1007/s00221-009-1719-3 
Journal of Eye Movement Research

9(7):2, 1-17

\section{Appendix}

Table A1

Musical stimuli characteristics: source, name of number of notes, number of measures, number of phrases and style of each score.

\begin{tabular}{llcccl}
\hline Stimuli source & Musical piece name & Notes & Meas. & S-Phrases & Style \\
\hline L. Alexander & El mago & 73 & 8 & 2 & Contemporary \\
& El payaso triste & $\mathbf{6 0}$ & $\mathbf{1 2}$ & $\mathbf{4}$ & \\
& Encantador de serpientes & 51 & 9 & 2 & \\
\hline Notenmappe & Morgen Lied & 87 & 10 & 5 & Tonal \\
& Gavotte & $\mathbf{8 5}$ & $\mathbf{9}$ & $\mathbf{4}$ & \\
& Joie du printemps & 76 & 17 & 4 & \\
\hline
\end{tabular}

Note. Meas $=$ number of measures. S-Phrases $=$ number of semi-phrase. In bold font scores selected for specific analysis. L. Alexander scores were taken from the book "El Pianista Chileno" (Botto, 1965).

Table A2

Verbal stimuli characteristics: Lexile ${ }^{\circledR}$ Measure, average length of sentences, number of words and style.

\begin{tabular}{lllllll}
\hline & Lexile ${ }^{\circledR}$ Measure & ALS & ALW & NW & Sentences & Style \\
\hline Text 1 & Graduate & 34.2 & 4.60 & 137 & 4 & Informative \\
Text 2 & A-level & $\mathbf{3 6 . 5}$ & $\mathbf{4 . 4 9}$ & $\mathbf{1 4 6}$ & $\mathbf{4}$ & Informative \\
Text 3 & Undergraduate & 26.5 & 4.59 & 106 & 4 & Informative \\
Text 4 & Graduate & $46.5 *$ & 4.60 & 186 & $3+2$ & Literary \\
Text $\mathbf{5}$ & A-level & $\mathbf{4 0 . 3}$ & $\mathbf{4 . 4 9}$ & $\mathbf{1 2 1}$ & $\mathbf{3}$ & Literary \\
Text 6 & Undergraduate & 42.75 & 4.59 & 171 & 3 & Informative \\
\hline
\end{tabular}

Note. $A L S=$ Average length of sentences; $A L W=$ average length of words; $N W=$ number of words. In bold font the texts selected for specific analysis. Standard score: $1410 \mathrm{~L}$ (graduate), 1320L (A-level), 1260 L (undergraduate).

* The entire first section is considered as a sentence. The final sentence has 99 words. 